\title{
Rationality and the Nature of the Market
}

\author{
Marco Castillo ${ }^{a}$ \\ Ragan Petrie ${ }^{\mathrm{b}}$ \\ Maximo Torero ${ }^{\mathrm{c}}$ \\ a School of Public Policy, Georgia Institute of Technology, Atlanta, GA 30332, USA \\ b Department of Economics, Georgia State University, Atlanta, GA 30303, USA \\ ${ }^{c}$ International Food Policy Research Institute, Washington, DC 20006, USA
}

September 2008

\begin{abstract}
We investigate the distribution of risk preferences and the frequency of expected utility violations along the gradient of market development. To do this, we collect experimental and survey data from a random sample of the population at four sites in Peru that differ in their level of competition and development. Similar to previous studies, we find that violations of expected utility theory are frequent. More importantly, however, violations are far less frequent the more competitive the market is. Also, our study suggests that experience in trade is not always associated with fewer behavioral anomalies. For instance, wholesale traders in an oligopolistic market with many years of experience are more likely to violate expected utility theory than entrepreneurs in an adjacent market with less experience. As hypothesized by Alchian (1950), it is in highly competitive markets where the evidence of rational behavior is found.
\end{abstract}

JEL classifications: C91, C93, D81.

Keywords: field experiments, rational behavior, competition, expected utility.

Acknowledgements: We thank Jim Cox and the participants at the GSU Experimental Economics Workshop for helpful comments. 


\section{Introduction}

Economists have long argued that market pressure, evolution or learning should eventually make people behave rationally. Alchian (1950) argued that not only would markets discipline behavior but that this would make it impossible to distinguish whether the success of a firm was due to shrewdness or luck. Later, Becker (1962) showed that aggregate behavior could satisfy basic properties of price theory even if individual behavior was random. Nowhere is it more clear that rational behavior can emerge endogenously than in evolutionary game theory (Weibull, 1995; Samuelson, 1997), which provides several examples of how evolutionary pressure can produce rational play in games. Similar examples of convergence to rational play can be found in the literature on learning (Fudenberg and Levine, 1998; Erev and Roth, 1998). That one might eventually reach seemingly rational behavior is important because it implies that regardless of one's initial limitations (cognitive or otherwise), basic economic intuition applies. But if Alchian (1950) was right and market forces shape behavior, we should also be cautious about the generality of policy recommendations. This paper presents experimental evidence showing that the competitiveness of the environment is indeed negatively correlated with the presence of behavioral biases.

To test how rational behavior is distributed across populations, we collect experimental data on random samples of four populations in Peru. The experiments were accompanied with rich survey data, allowing us to control for a series of potentially confounding effects. The experiments are based on a simple experiment first proposed by Chew and Waller (1986) and are designed to parsimoniously detect several violations of expected utility. The design is such that expected utility would predict a clear pattern of behavior. The choices made in the experiments, therefore, inform us of the kind of preferences producing violations. The key innovation of our design is that the experiments were conducted on dynamic, but not equally developed, economic areas.

Contrary to common procedures in experimental economics, the participant population was randomly selected. The sample includes two contigu-

ous economic markets in Lima-Peru, a highly competitive one composed of small garment entrepreneurs and a highly concentrated wholesale market. The third site is a dynamic peasant community in the Peruvian Andes, and the fourth is employees who currently work in the private sector. All the employees used to work in the public sector before it was privatized. Given 
the nature of the Peruvian economy and labor markets, the samples from the garment entrepreneurs and employees in the private sector represent competitive areas of the economy. The wholesale market and the peasant community represent more stable environments. Within each environment (competitive or stable), the groups differ in their level of development or endowments of human capital. The variation across these four sites therefore allows us to separate whether differences in behavior are simply a reflection of differences in socio-economic characteristics and initial endowments.

We confirm that a significant proportion of subjects violate the independence axiom as first shown by Allais (1953). This result persists under different specifications of errors in decision making (see Loomes et al. (2002) for a discussion of alternative methods). This is important because it shows that experimental methods can be utilized across diverse populations and produce robust results. Our nonparametric estimates show that violations of economic rationality correlate with age, education and risk aversion. Education diminishes the presence of violations, as does being young and risk neutral. However, these variables only explain a small portion of the violations. That behavioral biases are stronger among less educated and less developed areas gives support to the idea that the "poor but rational" paradigm of development is not necessarily appropriate (Duflo, 2003; Mullainathan, 2007). ${ }^{1}$

The discussion on what market or evolutionary pressures imply for the distribution of preferences has remained mainly theoretical (see Robson (2001) for a survey). ${ }^{2}$ Our work establishes that preferences and the economic envi-

\footnotetext{
${ }^{1}$ Some authors have suggested that risk averse (or impatient) behavior in low-stakes gambles, as the ones presented here, should be evidence of the failure of economic rationality and that behavior different from risk neutrality in experiments with small stakes would imply impossibly high levels of risk aversion (Rubinstein, 2006; Rabin, 2000; Benjamin, Brown, and Shapiro, 2006). Our experiments show that risk preferences over small stakes lotteries neither imply nor preclude violations of the independence axiom. This result is consistent with Cox and Sadiraj (2006)'s argument that risk preferences over small stakes is not a necessary nor sufficient condition for non-standard decision making under risk.

${ }^{2}$ There are as many examples showing that evolution will select rationality (and sometimes selfishness) as well as the opposite. Bergstrom and Stark (1993) and Eshel, Samuelson, and Shaked (1998) show that altruistic behavior can survive in an environment with local interactions. Robson (1996) shows that evolution does not necessarily produce rational behavior in non-stationary risky environments. Samuelson (2004) shows a model where nature finds it optimal to endow individuals with consumption comparison effects and Rayo and Becker (2007) and Netzer (2008) show that nature might find it necessary to endow humans with reference dependent preferences. Both these papers show that innate cognitive constraints might make some behavioral biases necessary. There are no models
} 
ronment are not orthogonal. This suggests that economic policy itself might have unintended consequences on preferences and that not all policies and institutions might work equally well across environments.

Other authors have investigated whether markets or experience can reduce behavioral biases (Brookshire and Coursey, 1987; Knez, Smith, and Williams, 1985; Coursey, Hovis, and Schulze, 1987). Using artefactual field experiments, List $(2003,2004)$ shows that experienced sport card traders are less likely to suffer from the endowment effect (Kahneman, Knetsch, and Thaler, 1991). ${ }^{3}$ Closest to our paper, List and Haigh (2005) show that stock market traders are less likely to conform to Allais' paradox than college students. ${ }^{4}$ Our experimental design is different in that we include five lottery questions to check the robustness of the violations and to distinguish among competing alternative theories to expected utility. Also, in an attempt to increase the external validity of our results, our experimental design relies on random samples of the population of interest. More importantly, by varying market competition and levels of development our results show that it is not market experience per se, but the nature of the market itself, that is correlated with the preferences of participants. ${ }^{5}$

This would suggest that caution is in order when making general statements about what model of human behavior is most appropriate. Some authors have suggested that cognitive abilities, which are likely correlated with economic development, are important in explaining behavioral biases (Casari, Ham, and Kagel, 2007; Benjamin, Brown, and Shapiro, 2006). Our research shows that independent of the personal characteristics of the subjects, the environment where they make their living most strongly correlates with their economic preferences.

The paper is organized as follows. Section 2 describes the experimental design. Section 3 describes the data and the sample of subjects. Section 4 presents non-parametric estimations on the distribution of preferences. Sec-

giving an evolutionary basis to Allais' paradox.

${ }^{3}$ Plott and Zeiler (2007) have pointed out that trading asymmetries cannot necessarily be attributed to endowment effects and Koszegi and Rabin (2006) argue that behaviorallybiased subjects expecting to trade will not incur trading asymmetries.

${ }^{4}$ In List and Haigh (2005)'s paper, experience and the nature of the market, i.e. competitive or not, move in the same direction. So, it is not possible to identify them separately. In our experiment, they move in opposite directions.

${ }^{5}$ Our experiment tests violations of expected utility, so we cannot add to the discussion of experience and the endowment effect. 
tion 5 presents parametric estimates of value functions and decision weights as a function of personal characteristics. Section 6 concludes.

\section{Design and Sample Selection}

\section{$2.1 \quad$ Experimental Design}

There is a large body of experimental literature that tests alternative models of decision making under uncertainty (Camerer, 1993; Hey and Orme, 1994; Harless and Camerer, 1994; Chew and Waller, 1986; Sopher and Gigliotti, 1993). This paper uses the HILO lottery structure first introduced by Chew and Waller (1986) to generalize Allais (1953)'s original design. The design requires three potential ordered outcomes $x_{L}<x_{I}<x_{H}$ and two alternative lotteries: $A=\left(x_{M}, 1\right)$ and $B=\left(x_{L}, 1-\alpha ; x_{H}, \alpha\right)$, referred to as pair $O$. To construct lotteries as in Allais (1953), the design creates compound lotteries as follows:

$A_{i}=\beta A+(1-\beta) x_{i}$ and $B_{i}=\beta B+(1-\beta) x_{i}$ for $i=L, I, H$

In our design, $x_{L}=0, x_{I}=50 c$, and $x_{H}=100 c$. For simplicity of interpretation, the probability weights we use are $\alpha=0.8$ and $\beta=0.25$. The classic Allais design is obtained by comparing lottery pair $I$ and lottery pair $L$. Figure 1 presents all lotteries used in our experiments in the MarshackMachina triangle (Machina, 1987). Pairs 1 and 2 reproduce Allais' design, pairs 2 and 5 allow to test for either fanning-out or fanning-in (Machina, 1987), and comparisons of pair 1, 3 and 4 provide a direct test of the inbetweenness hypothesis.

The HILO design is attractive due to its compactness and ability to test different generalizations of expected utility theory in an efficient way. While expected utility predicts that a person will choose either $S_{i}$ or $R_{i}$, for all lotteries $i$, alternative theories predict different patterns of behavior (see Harless and Camerer (1994), for details). As noted by Sopher and Gigliotti (1993), Conlisk (1989) and Camerer (1993), this design might favor alternative theories to expected utility due to the fact that lotteries are located on the borders of the Marshack-Machina triangle. In that sense, this design might reject the null hypothesis of expected utility too often. In order to increase the power of our tests, our design includes an extra pair of lotteries, pair 4.

To elicit risk preferences, subjects were asked to respond to a series of simple lotteries that includes the lotteries represented in Figure 1 and two 
additional lotteries to measure risk attitudes. The extra two lotteries are a simplified version of the lotteries first used by Binswanger (1981). Subjects were asked to choose one of five risky prospects that gave a high and low payoff with equal probability. The lotteries are listed in Table 2. They were constructed by either adding $30 \times k$ or subtracting $10 \times k, k=1, \ldots, 4$, to an initial high and low payoff of $(50,50)$ or $(0,0)$. The first set of lotteries therefore were over gains and the second over gains and losses. The units of the lottery were cents of the local currency. ${ }^{6}$ The lottery payments were set large enough to be salient, but small enough to afford a large number of observations.

The experimental procedures were as follows. After firm/household surveys were administered, in a separate visit from the visits for the surveys, the lottery questions were asked. Subjects were asked to make their lottery decision over gains, then over gains and losses and then over the extra five lotteries to test for violations of expected utility theory. Once decisions were made, the lotteries designed to measure risk were resolved by flipping a coin, and the five rationality lotteries were resolved by choosing a number between one and twenty out of a bag. Subjects were then paid in cash the sum of their earnings. Subjects knew of these procedures before making their decisions.

\subsection{Sample Selection}

The study was conducted with four different populations that represent sectors of the Peruvian economy: employees currently in the private sector (who were previously in the public sector), entrepreneurs of Gamarra's garment district in Lima, vegetable traders in the neighboring Santa Anita's wholesale market in Lima, and farmers of the peasant community of Pomacanchis in the Andes. The four groups showcase the large disparities in economic achievement common in most developing countries.

In all four sites, the sampling framework was built from a census of the firms or households in the area. In Gamarra, Santa Anita and Pomacanchis, we conducted a census of the entire area and then randomly selected firms or households from to survey. In Gamarra and Santa Anita, the manager of the firm was interviewed. In Pomacanchis, the head of the household was interviewed. In the private sector, we used the census of privatized

\footnotetext{
${ }^{6}$ One hundred cents, or 1 sol, could buy a person lunch at the time of the survey. Participants made seven paid decisions which amounted to around five to seven soles per person.
} 
firms done by the Ministry of Labor and developed a sampling framework stratified by firm size. Employees within the firm were randomly selected to be interviewed.

Employees in the private sector of the economy were all previously employed in the public sector. They obtained a professional and/or technical degree in order to perform their job, i.e. subjects in this sample either entered the job market as professionals or technicians or acquired those skills through on-the-job training. After economic reforms in the early 1990's and a massive reduction in the public sector (Saavedra and Torero, 2004), this group faced a large increase in the level of competition. Firm ownership changed to private hands, and the labor market was deregulated. The labor market in Peru is extremely competitive, and many subjects in this sample are either unemployed or under-employed and perform jobs different from those for which they were trained. ${ }^{7}$ Most researchers think that this sector represents the formal sector of the economy (i.e., tax-payers with access to social services). The average length of time a person keeps a job in this sector decreased by $25 \%$ after labor market reforms were implemented (Saavedra and Torero, 2004; Torero, Deustua, and Hernandez, 2007).

Gamarra is a fast-growing economic cluster of entrepreneurs and is full of firms involved in small-scale manufacturing and trade. Most of Gamarra's entrepreneurs are migrants that started their business outside the formal financial system. Until the early 1990's, this sector faced little regulation or support. ${ }^{8}$ Gamarra is a 12 square block area in Lima, Peru. It emerged in the 1960 's as an area where migrants started small textile businesses to supply the growing garment industry. Since its inception, the area has attracted migrants and entrepreneurs for its agglomeration economies. Now, the area hosts thousands of small firms engaged in small manufacturing (i.e. retail, consumption and wholesale goods) and trade. Because of their size, firms are capable of quickly adapting production to the needs of the market. This makes the area dynamic and attractive to those willing to take risks. It is also a highly competitive sector. For example, when we asked the entrepreneurs how many competitors they face, $48 \%$ reported that they had more than 5 competitors in the same location.

\footnotetext{
${ }^{7}$ It is important to realize that technical or professional training is a relative term in Peru. The local education system is of extremely poor quality and potential employees can access well-developed markets for counterfeit certificates and education degrees.

${ }^{8}$ In 1995, a new simplified tax system was implemented to make it possible for small businesses to pay taxes. Further modifications were introduced in 2003.
} 
Santa Anita's vegetable wholesale market has been the largest fresh produce distribution center in Lima until recently. This market was established around the same time Gamarra started. Most of the traders in this sector are migrants as well. Contrary to Gamarra, this market is monopolistic with few traders dominating most of the vegetable market in Lima. Most of the current traders started as intermediaries, buying fresh produce directly from producers and then transporting it to the city. They eventually grew enough to become buyers from smaller intermediaries and now provide fresh produce to all main markets in Lima. The market is divided into sections, with few buyers per product.

The peasant community of Pomacanchis was selected because it has a large rural population and significant economic activity. Pomacanchis District is located in Acomayo Province in Cusco. It is an agricultural (potato) and livestock area in which several development programs of different NGOs operate. While poor, the community has easy access to local and regional markets. Producers in this community depend on the market to sell part of their production and obtain inputs and household items. The community is representative of rural life in a developing country. That is, while partially integrated into some markets, they have limited or no access to credit and insurance markets and lack access to health care and most public services. Nonetheless, the community has electricity and access to phone and the internet. The structure of land, property and production has changed little since early studies of the area by Cotlear (1989) and Escobal (1994). This stability is not surprising given that Escobal and Castillo (1992) show that peasant economies are particularly resilient to large price fluctuations.

Table 1 presents basic summary statistics for the four subsamples. It shows that the garment district attracts somewhat younger individuals. All four sites have similar proportions of household/firms headed by men. An important difference across these populations is the level of education. Private sector employees tend to be more educated than people working in the garment sector, who in turn, are more educated than those in the wholesale market. Those in the peasant community are the least educated of all groups. It is natural to find a correlation between market development and education. Most competitive sectors tend to require and select more educated individuals. ${ }^{9}$ The second to last row of Table 1 provides a measure of

\footnotetext{
${ }^{9}$ While there are enormous barriers to entry into the wholesale market, entry and durability in the wholesale market requires business savvy.
} 
job or firm rotation in all four populations. On average, employees in the private sector have held their current jobs for 5.4 years. The life span of firms in the garment sector is 6.9 years and that of firms in the wholesale market is 21.7 years. Farmers in the peasant community have been doing this since an early age, i.e., they have been in this activity for 22.5 years. ${ }^{10}$

\section{Empirical Analysis}

This section discusses general patterns in the experimental data. Two subsections discuss parametric and non-parametric estimates of preferences.

\subsection{Patterns of Behavior}

Table 2 presents the distribution of choices in the seven lotteries presented to participants. The data is disaggregated by subpopulation to highlight the patterns of behavior. The top two panels of Table 2 present the results for lotteries over gains and over gains and losses. The bottom panel presents the distribution of choices for the lotteries testing the validity of the independence axiom.

In the top two panels, the lotteries over gains and gains and losses offer risky prospects that increase simultaneously in expected payoffs and variances. Given the size of the stakes, one could argue that subjects should choose according to expected values. Table 2 shows that the average behavior of subjects from all walks of life is not to do this. We do not observe a clear pattern of risk attitudes across populations. The only exception is that farmers in the peasant community are the most risk averse subjects in the sample, with $46 \%$ choosing the safest option. Interestingly, there is a clear tendency to choose higher expected value lotteries over gains and losses among those working as employees in the private sector. These subjects are more likely to choose the higher paying lotteries when the lotteries allow losses compared to when they are defined over gains only. A similar pattern is observed at the other extreme of the development spectrum. Farmers choose riskier lotteries when losses are allowed. This pattern is not consistent with loss-aversion.

\footnotetext{
${ }^{10}$ People in Pomacanchis have spent their lives farming with only a short break due to mandatory military service. We calculated the lower bound of the time performing this activity by assuming that every farmer in our sample started farming at age 25 .
} 
The bottom panel of Table 2 presents the distribution of choices over the HILO lotteries. Each pair of numbers in each column presents the number of subjects choosing the safe lottery and the number of subjects choosing the riskier lottery. The results only present the marginals of the joint distribution of choices over all lotteries. Since, violations of expected utility might happen by mistake, one would expect that on average the proportion of subjects choosing safe and riskier alternatives remains similar across lotteries. Lotteries 1 and 2 are consistent with Allais' presentation. The switch from safe choices in Lottery 1 to risky choices in Lottery 2 is referred to as Allais' paradox. Table 2 shows that the Allais paradox is not equally prevalent in all populations. ${ }^{11}$ Employees in the private sector and managers in the garment industry are the least likely to suffer from it, whereas wholesale traders and farmers are the most likely.

Figure 1 shows that lotteries 1, 3 and 4 are all located along the same line. Any theory of decision under risk satisfying the in-betweenness axiom would predict that subjects will choose similarly across these three lotteries. This does not occur in any of the populations under study. Violations of in-betweenness seem to be most severe among wholesale traders. Finally, comparison of lotteries 2 and 5 allows us to test for the fanning-out hypothesis (Machina, 1987). The evidence in favor of this hypothesis is weak and consistent with previous research (see Chew and Waller (1986); Harless and Camerer (1994); Conlisk (1989)).

In summary, this section shows that the distribution of risk preferences is not uniformly distributed across populations and that more competitive areas tend to be populated by agents closer to the expected utility paradigm.

\subsection{Identifying Preferences - Nonparametric Estimates}

We look first at nonparametric estimates and turn to parametric estimates in the next section. The estimates allow a look at the distribution of preferences and for the possibility that subjects make judgement or decision errors.

\footnotetext{
${ }^{11}$ The same results hold if we control for the decisions that the subject made in the gain-gain and gain-loss lotteries.
} 


\subsubsection{Distribution of Behavior}

Several authors have discussed alternative ways to unearth underlying risk preferences when decisions are made with error. ${ }^{12}$ We follow Harless and Camerer (1994). The basic intuition behind these approaches is that, given a subject's preferences, different error structures will produce different patterns of observed behavior. For instance, in our experimental design, expected utility theory allows only two patterns of behavior: RRRRR and SSSSS. If a person makes one mistake only, possible patterns of behavior will be: SRRRR, RSRRR, RRSRR, RRRSR, RRRRS, RSSSS, SRSSS, SSRSS, SSSRS, SSSSR. If this subject makes a mistake with probability $\epsilon$ and the proportion of people that have preferences supporting pattern RRRRR is $p_{R R R R R}$, then the probability of observing pattern of behavior SRRRR is $p_{R R R R R} \times \epsilon \times(1-\epsilon)^{4}+\left(1-p_{R R R R R}\right) \times \epsilon^{4} \times(1-\epsilon)$. A well-specified likelihood function can be constructed for any theory of behavior under risk following analogous reasoning. Different theories that allow different patterns of behavior are potentially discernible with enough data.

We present estimates for five theories of behavior under risk for our four different populations in Tables 3a,b,c,d and e. The five models are: expected utility theory (EU), rank dependent expected utility theory with concave probability weights (RD-cave), rank dependent expected utility theory with convex probability weights (RD-vex), the mixed fanning hypothesis (MF), and prospect theory (PT). All the estimates are based only on the four original HILO lotteries, i.e., lotteries 1, 2, 3 and 5. The estimates are similar if lottery 4 is also included. ${ }^{13}$ Our analysis concentrates on the above mentioned theories only because they allow a number of patterns observed in the data and they contain most of the patterns of behavior predicted by other theories.

Table 3 presents choices in the following order: Lottery 3, Lottery 1, Lottery 2, and Lottery $5 .^{14}$ Lottery 3 is the original lottery upon which Chew and Waller (1986) construct all others lotteries. This is lottery O in Chew and Waller (1986)'s terminology. The first, second, and fifth lotteries

\footnotetext{
${ }^{12}$ Hey and Orme (1994) uses a random utility model to estimate preferences of experimental subjects. Harless and Camerer (1994) propose an error model to estimate alternatives models with aggregate data. Loomes, Moffatt, and Sugden (2002) discusses several alternative ways to model decisions made with error.

${ }^{13}$ These are available from the authors upon request.

${ }^{14}$ The lotteries are presented in this order to make them comparable to the presentation in Harless and Camerer (1994)
} 
are obtained by mixing Lottery 3 with the middle, low and high outcome (lotteries I, L, and H), as shown in the experimental design section.

Table 3a shows the patterns of behavior and estimates for all the subjects in our experiments. These patterns are difficult to reconcile with maximization of expected value. For instance, of all the patterns that allow exactly one deviation from RRRR, pattern RRSR appears 110 times out of 358 . This is slightly less than a third of the time or roughly twice as frequent as would be predicted if one deviation from RRRR was random over the four possible one-deviation patterns. Of all the choices, 26 percent are consistent with Allais' paradox. Table 3a also presents a test of the hypothesis that expected utility is a valid restriction of more general models of decision making under uncertainty. For instance, the last row of the fourth column tests the null hypothesis that the probability that all extra patterns of behavior allowed by RD-vex is zero. The test has 7 degrees of freedom (9 patterns of behavior allowed by RD-vex minus 2 allowed by EU). It shows that the hypothesis cannot be rejected. However, the hypothesis is rejected for all the other alternative theories at any standard level of significance.

Similar estimates for each one of the four subpopulations in our study are presented in Tables 3b, 3c, 3d, and 3e. Notice that patterns identified in the aggregate data are reproduced in all the subsamples. The explanatory power of rank dependent expected utility with a convex weighting function is poor in every one of these populations. The other three theories perform better than expected utility and RD-vex in all four subsamples. The likelihood ratio test does not allow us to determine what theory is best overall. Each theory seems to miss some important observed pattern of behavior.

The nonparametric approach permits us to obtain conservative estimates of the prevalence of expected utility agents in the data. This is so because the estimates account for potential errors in judgement, as well as alternative patterns of behavior. Ignoring RD-vex, that has a poor fit for the data, we can calculate the probability that an agent choose either SSSS or RRRR for each population and each model. A clear pattern emerges: the presence of behavior consistent with expected utility is different across populations.

Among farmers, the proportion consistent with expected utility is between 45-60 percent. Among wholesale market traders the proportion is between 50-52 percent. Among managers in the garment industry, the proportion consistent with expected utility theory is between 65-78 percent. Finally, among the employees in the private sector, the percent fluctuates between 70-90. The comparison between wholesale traders and garment industry 
managers is particularly interesting because these two populations neighbor each other geographically and share many socio-economic characteristics and background.

\subsubsection{Rationality and Demographics}

We are also interested in knowing if expected utility maximizers in the population are related to covariates. To do so, we look at the prevalence of this group by risk aversion, age and education-Tables 1 and 2 make clear that the populations in the study differ across these three variables. Estimates of the Harless and Camerer (1994) model for different cuts of the data are shown in Table 4. For instance, the first panel compares the distribution of preferences of those without and with high school education. The estimates show that higher levels of education are correlated with the presence of expected utility maximizers. For instance, using estimates of prospect theory, we find that those with at least high school education are 20 percentage points more likely to behave according to expected utility. Mixed fanning estimates give an estimate half this size. While there are differences across education levels, the estimates show that neither age nor sex explain much of the variation in the distribution of preferences.

Looking now at risk preferences, the last panel shows the behavior of those choosing less risky choices (one of the first two lotteries) with those choosing more risky choices (one of the last two lotteries) over the gain lottery. ${ }^{15}$ Here we find large differences in the distribution of preferences between these two groups. Those who chose more risky lotteries are between 15-20 percentage points more likely to conform with EU while those choosing less risky choices deviate strongly. This suggests that risk aversion over small stakes is positively correlated with the presence of behavioral biases. However, it could also signal that the experiments are calibrated for relatively high levels of risk aversion. ${ }^{16}$ This would imply that our estimates underestimate the presence of behavioral biases among relatively less risk averse subjects.

In order to test whether differences in risk attitudes and education explain the differences in behavior across sites, we estimate the model by location and personal characteristics. Table 5 presents data across populations for

\footnotetext{
${ }^{15}$ We use the gain lottery because it exhibits the most variation.

${ }^{16}$ If our lotteries were re-calibrated such that the risky and safe lotteries were along a line parallel to the 45-degree line, we might find more deviations among those choosing riskier options.
} 
those that chose less risky lotteries over gains and those that choose riskier lotteries. Table 6 presents estimates across populations for those with less than high school education and those with at least high school education.

Two patterns emerge in the data. First, differences across populations are smaller for those that behave more risk aversely and for those with less than high school education. Table 5 and Table 6 show that some important differences remain in the case of education. The strongest differences are between public sector employees with less than high school education and those with at least high school education. Also large differences across populations remain if we restrict ourselves to the sample of educated and less risk averse. ${ }^{17}$ That is, the existing differences across these populations cannot be attributed only to differences in observable characteristics. The differences across populations are particularly large among those with at least high school education. These results are therefore consistent with either sorting or with learning through market experience.

The fact that there are fewer expected utility maximizers among wholesale market traders is particularly interesting. As mentioned before, this population shares the background of the managers in the garment district. Indeed, these two populations share contiguous geographical spaces. However, one population is more consistent with expected utility maximization than the other. We cannot argue that wholesale traders do not have market experience since their activity is indeed to trade. So, we cannot attribute economic rationality to experience with trading per se. A large difference between these two sectors is that one is extremely concentrated and the other is extremely competitive. Economic rationality therefore seems to be correlated with experiencing competitive pressures rather than trading itself. The fact that those working in a competitive labor market tend to be more consistent with expected utility theory supports this hypothesis. ${ }^{18}$

\footnotetext{
${ }^{17}$ These results are not shown in the paper but are available from the authors upon request.

${ }^{18}$ To test whether experience or competition increases rational behavior, we compared the behavior of less and more experienced managers in the garment industry. Since the survival rate of new firms in this sector is small, one would expect that new firms will experience relatively more market competition (unless they are a spin-off of larger firms). Consistent with the importance of competition, we find that inexperienced managers tend to be between 5-20 percent more likely to satisfy expected utility depending on the model adopted.
} 


\subsection{Identifying Preferences - Parametric Estimates}

The previous section suggests that socio-economic background could explain differences across experimental sites. In this section, we adapt Harless and Camerer (1994)'s model to allow the probability of behaving according to expected utility to depend parametrically on covariates. This allows us to control for a variety of covariates at a time and obtain estimates that allow for statistical testing.

Let M1 be an alternative model to expected utility (EU) and let $x$ be an observed pattern of behavior. The law of total probability establishes that:

$$
\operatorname{Pr}(x)=\operatorname{Pr}(x \mid E U) \times \operatorname{Pr}(E U)+\operatorname{Pr}(x \mid M 1) \times(1-\operatorname{Pr}(E U))
$$

where $\operatorname{Pr}(x \mid T)$ is the conditional probability of observing pattern $x$ given theory $T$, and $\operatorname{Pr}(E U)=F(z \beta) . \quad F$ is a cumulative function that maps index $z \beta$ to the interval $[0,1]$. $z$ represents a list of covariates. In this paper, we assume that $F$ follows a logistic form. ${ }^{19}$ This statistical model allows the estimation of the probability of conforming to expected utility theory without imposing parametric restrictions on the form the utility function or weighting function must take.

The estimates for each of the four alternative models discussed so far are presented in Table 7. The top panel presents the estimates corresponding to the proposed behavioral model, and the middle panel presents the estimates for expected utility theory as compared to that alternative behavioral model. The bottom panel present the logistic share equation described above. The share equation controls for sex, age, and education. Three dummies are added to test if any remaining difference between places exists after controlling for socio-economic background. The omitted category is the wholesale vegetable market.

Since, as in previous estimations, the RD-vex model does a poor job in describing the data, all the discussion concentrates on the three remaining models. The first result is that no socio-demographic variables seem to be good predictors of behavior in the experiments. This suggests that the differences in behavior observed in the nonparametric estimations reflect the

\footnotetext{
${ }^{19}$ We also used a latent class model to make comparisons across experimental sites. A problem with latent class models is that they depend on untestable parametric assumptions of the utility function and the probability weighting function. Estimates using Prelec (1998)'s weighting function produced similar results.
} 
difference in socio-demographic variables across experimental sites, not the effect of these variables on behavior. Our sample has enough within and between variation to identify these differential effects.

The parametric estimates show that the differences in behavior between private sector employees and entrepreneurs versus that of whole traders and peasants is not due to differences in socio-economic background. All three models show that private sector employees are more likely to conform to expected utility and two models (RD-cave and PT) predict the same for the garment industry entrepreneurs. The estimates also show that the probability of satisfying expected utility theory is between $58 \%$ and $59 \%$ in the garment industry district and between $85 \%$ and $86 \%$ among private sector employees. This number is only between $39 \%$ and $40 \%$ in the wholesale market. ${ }^{20}$

The strong showing of expected utility maximizers in the private sector is particularly illuminating. This sector started out mainly based on rent extraction (when it was the public sector). Now, it is based on competition. These results suggest that the experience of market competition is important to the survival of behavioral biases.

\section{Conclusions}

We investigate the relationship between market structure and the presence of behavioral biases in decision making under risk. From a random sample of individuals working in unequally developed markets, we collect data on a series of experiments designed to detect the nature of expected utility violations. The markets visited differ not only in their depth but also in their level of competition.

We find that market experience alone is not enough to eliminate violations of expected utility theory. Evidence of violations persist among participants in all the visited markets and especially among those with a lot of trading experience. We find that behavioral biases are weaker in markets that are more competitive. For instance, we find that wholesale traders that trade on a daily basis but do so in a concentrated, noncompetitive market are among the ones most likely to violate expected utility theory. Entrepreneurs, in an adjacent market who trade daily but do so in a highly competitive market,

\footnotetext{
${ }^{20}$ These estimates assume that all parameters that are not significant are zero except the constant.
} 
are more likely to satisfy expected utility. While violations of expected utility theory are correlated with education and attitudes toward risk, we find that when controlling for both neither one can completely explain the differences found across populations.

Our results show that preferences are not distributed equally across markets and that experience with trade does not necessarily foster rationality. Consistent with the intuition that evolutionary pressure is important in the selection of preferences, we find that competitive markets either attract or create individuals closer to the neoclassical economic paradigm. Our results suggests that economic policy itself can have consequences on the decisions that people make. This would suggest that policy evaluation cannot assume preferences as given. 


\section{References}

A. Alchian. Uncertainty, evolution, and economic theory. Journal of Political Economy, 58(3):211-21, 1950.

M. Allais. Le comportement de l'homme rationnel devant le risque: Critique des postulats et axiomes de l'ecole americaine. Econometrica, 21(4):503$546,1953$.

G. Becker. Irrational behavior and economic theory. Journal of Political Economy, 70(1):1-13, 1962.

D. Benjamin, S. Brown, and J. Shapiro. Who is behavioral? cognitive ability and anomalous preferences. Working Paper, University of Chicago, 2006.

T. Bergstrom and O. Stark. How altruism can prevail in an evolutionary environment? American Economic Review, 83(2):149-155, 1993.

H. Binswanger. Attitudes toward risk: Theoretical implications of an experiment in rural india. Economic Journal, 91(364):867-890, 1981.

D. Brookshire and D. Coursey. Measuring the value of a public good: An empirical comparison of elicitation procedures. American Economic Review, 77(4):554-568, 1987.

C. Camerer. An experimental test of several generalized utility theories. Journal of Risk and Uncertainty, 2:61-104, 1993.

M. Casari, J. Ham, and J. Kagel. Selection bias, demographic effects, and ability effects in common value auction experiments. American Economic Review, 97(4):1278-1304, 2007.

S. Chew and W. Waller. Empirical tests of weighted utility theory. Journal of Mathematical Psychology, 30:55-62, 1986.

J. Conlisk. Three variants on the allais example. American Economic Review, 79(3):392-47, 1989.

D. Cotlear. Desarrollo campesino en los andes: cambio tecnologico y transformacion social en las comunidades de la sierra del Peru. Instituto de Estudios Peruanos, Lima, Peru, 1989. 
D. Coursey, J. Hovis, and W. Schulze. The disparity between willingness to accept and willingness to pay measures of value. Quarterly Journal of Economics, 102(3):679-691, 1987.

J. Cox and V. Sadiraj. Small- and large-stakes risk aversion: Implications of concavity calibration for decision theory. Games and Economic Behavior, 56(1):45-60, 2006.

E. Duflo. Poor but rational? Working Paper, Harvard University, 2003.

I Erev and A. Roth. Predicting how people play games: Reinforcement learning in experimental games with unique, mixed strategy equilibria. American Economic Review, 88(4):848-81, 1998.

J. Escobal. Impacto de las politicas de ajuste sobre la pequena agricultura. Debate Agrario, 20:51-76, 1994.

J. Escobal and M. Castillo. Politica de precios en el agro, distribucion del ingreso e insercion al mercado: una nota metodologica. Debate Agrario, 13(enero-mayo):69-81, 1992.

I. Eshel, L. Samuelson, and A. Shaked. Altruists, egoists, and hooligans in a local interaction model. American Economic Review, 88:157-180, 1998.

D. Fudenberg and D. Levine. The Theory of Learning in Games. MIT Press, Cambridge and London, 1998.

D. Harless and C. Camerer. The predictive utility of generalized expected utility theories. Econometrica, 62(6):1251-1289, 1994.

J. Hey and C. Orme. Investigating generalizations of expected utility theory using experimental data. Econometrica, 62(6):1291-1326, 1994.

D. Kahneman, J. Knetsch, and R. Thaler. Anomalies: The endowment effect, loss aversion, and status quo bias. Journal of Economic Perspectives, 5(1): 193-207, 1991.

P. Knez, V. Smith, and A. Williams. Individual rationality, market rationality, and value estimation. American Economic Review, 75(2):397-403, 1985. 
B. Koszegi and M. Rabin. A model of reference-dependent preferences. Quarterly Journal of Economics, 121(4):1133-1165, 2006.

J. List. Does market experience elimate market anomalies? Quarterly Journal of Economics, 118(1):41-71, 2003.

J. List. Neoclassical theory versus prospect theory: Evidence from the marketplace. Econometrica, 72(2):615-625, 2004.

J. List and S. Haigh. A simple test of expected utility theory using professional traders. Proceeding of the National Academy of Sciences, 102: 945-948, 2005.

G. Loomes, P. Moffatt, and R. Sugden. A microeconometric test of alternative stochastic theories of risky choice. Journal of Risk and Uncertainty, 24(2):103-130, 2002.

M. Machina. Choice under uncertainty: Problems solved and unsolved. Journal of Economic Perspectives, 1:121-154, 1987.

S. Mullainathan. Development economics through the lens of psychology. Working Paper, Massachussets Institute of Technology, 2007.

N. Netzer. Evolution of time preferences and attitudes towards risk. American Economic Review, forthcoming, 2008.

C. Plott and K. Zeiler. Exchange asymmetries incorrectly interpreted as evidence of endowment effect theory and prospect theory? American Economic Review, 97(4):1449-1466, 2007.

D. Prelec. The probability weighting function. Econometrica, 66(3):497-527, 1998.

M. Rabin. Risk aversion and expected-utility theory: A calibration theorem. Econometrica, 68(5):1281-1292, 2000.

L. Rayo and G. Becker. Evolutionary efficiency and happiness. Journal of Political Economy, 115(2):302-337, 2007.

A. Robson. A biological basis for expected and non-expected utility. Journal of Economic Theory, 68:397-424, 1996. 
A. Robson. The biological basis of economic behavior. Journal of Economic Literature, 39(1):11-33, 2001.

A. Rubinstein. Dilemmas of an economic theorist. Econometrica, 74(4): 865-883, 2006.

J. Saavedra and M. Torero. Labor market reforms and their impact over formal labor demand and job market turnover: The case of peru. In J. Heckman and C. Pages, editors, Law and Employment: Lessons from Latin America and the Caribbean. National Bureau of Economic Research Conference Report, 2004.

L. Samuelson. Evolutionary games and equilibrium selection. MIT Press, Cambridge and London, 1997.

L. Samuelson. Information-based relative consumption effects. Econometrica, 72:93-119, 2004.

B. Sopher and G. Gigliotti. A test of generalized expected utility. Theory and Decision, 35(1):75-106, 1993.

M. Torero, J. Deustua, and M. Hernandez. Abriendo la caja negra de las privatizaciones. In GRADE, editor, Investigacin, Polticas y Desarrollo en el Peru, pages 351-402. GRADE, Lima, Peru, 2007.

J. Weibull. Evolutionary Game Theory. MIT Press, Cambridge and London, 1995. 


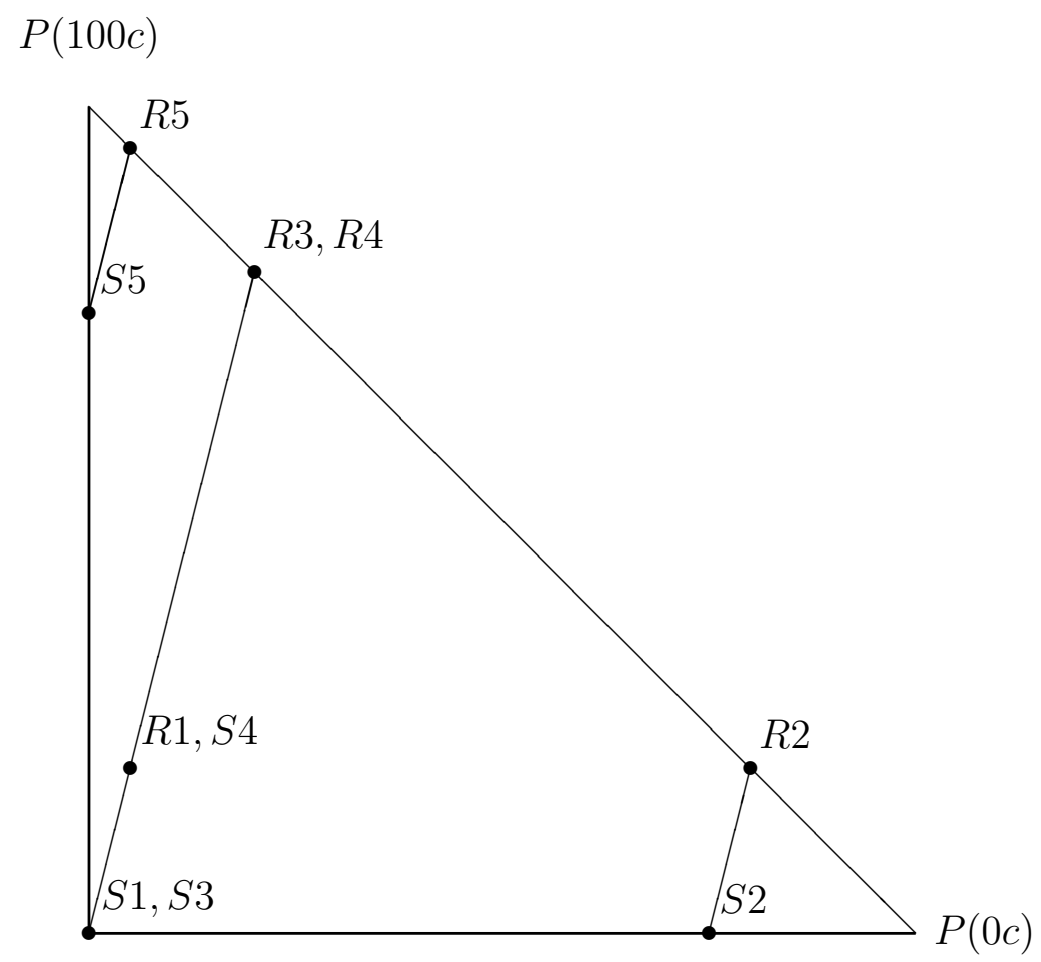

Figure 1. Lotteries in the Marschak-Machina triangle 
Table 1. Descriptive Statistics

\begin{tabular}{ccccc} 
Variable & $\begin{array}{c}\text { Private } \\
\text { Sector }\end{array}$ & $\begin{array}{c}\text { Garment } \\
\text { Industry }\end{array}$ & $\begin{array}{c}\text { Wholesale } \\
\text { Traders }\end{array}$ & $\begin{array}{c}\text { Peasant } \\
\text { Community }\end{array}$ \\
\hline Age & $50.84(0.362)$ & $42.89(0.678)$ & $51.77(0.851)$ & $47.53(0.759)$ \\
Male & $0.85(0.014)$ & $0.87(0.020)$ & $0.85(0.024)$ & $0.83(0.020)$ \\
Primary Ed. & $0.12(0.012)$ & $0.14(0.020)$ & $0.31(0.031)$ & $0.19(0.020)$ \\
Secondary Ed. & $0.39(0.019)$ & $0.54(0.029)$ & $0.43(0.033)$ & $0.08(0.014)$ \\
College Ed. & $0.47(0.019)$ & $0.30(0.027)$ & $0.19(0.026)$ & $0.03(0.009)$ \\
Emp. Duration (Years) & $5.39(0.165)$ & $6.89(0.390)$ & $21.69(0.785)$ & $22.53(0.759)$ \\
Observations & 669 & 300 & 228 & 384 \\
\hline
\end{tabular}

Note: standard errors in parentheses 


\section{Table 2. Experimental Results}

\begin{tabular}{|c|c|c|c|c|}
\hline & $\begin{array}{l}\text { Private } \\
\text { Sector }\end{array}$ & $\begin{array}{l}\text { Garment } \\
\text { Industry }\end{array}$ & $\begin{array}{c}\text { Wholesale } \\
\text { Traders }\end{array}$ & $\begin{array}{c}\text { Peasant } \\
\text { Community }\end{array}$ \\
\hline Lottery & \multicolumn{4}{|c|}{ Gains $\& 3$ Gains Lotteries (Percent) } \\
\hline$(50,50)$ & $143(21)$ & $54(18)$ & $57(25)$ & $177(46)$ \\
\hline$(80,40)$ & $122(18)$ & $66(22)$ & $23(10)$ & $55(14)$ \\
\hline$(110,30)$ & $91(14)$ & $62(21)$ & $29(13)$ & $42(11)$ \\
\hline$(140,20)$ & $77(12)$ & $57(19)$ & $40(18)$ & $29(8)$ \\
\hline$(170,10)$ & $236(35)$ & $61(20)$ & $79(35)$ & $81(21)$ \\
\hline Lottery & \multicolumn{4}{|c|}{ Gains $\& 3$ Losses Lotteries (Percent) } \\
\hline$(0,0)$ & $91(14)$ & $94(31)$ & $107(47)$ & $73(19)$ \\
\hline$(30,-10)$ & $53(8)$ & $80(27)$ & $39(17)$ & $90(23)$ \\
\hline$(60,-20)$ & $103(15)$ & $58(19)$ & $25(11)$ & $83(22)$ \\
\hline$(90,-30)$ & $105(16)$ & $52(17)$ & $39(17)$ & $89(23)$ \\
\hline$(120,-40)$ & $317(47)$ & $16(5)$ & $18(8)$ & $49(13)$ \\
\hline Lottery & \multicolumn{4}{|c|}{ HILO Lotteries (Safe, Risky) - Numbers } \\
\hline 1 & $(159,510)$ & $(107,193)$ & $(115,113)$ & $(172,212)$ \\
\hline 2 & $(147,522)$ & $(80,220)$ & $(39,189)$ & $(83,301)$ \\
\hline 3 & $(112,557)$ & $(82,218)$ & $(70,158)$ & $(147,237)$ \\
\hline 4 & $(157,512)$ & $(91,209)$ & $(40,188)$ & $(128,256)$ \\
\hline 5 & $(120,549)$ & $(78,222)$ & $(38,190)$ & $(90,294)$ \\
\hline
\end{tabular}

Note: In the top two panels, the last four columns list the number (and the percent) who chose each lottery. In the bottom panel, each pair lists (the number choosing the safe lottery, the number choosing the riskier lottery) 
Table 3a. Whole Sample

\begin{tabular}{|c|c|c|c|c|c|c|}
\hline \multirow[t]{2}{*}{ Pattern $^{a}$} & \multirow[t]{2}{*}{ Frequency } & \multirow{2}{*}{$\begin{array}{c}\text { Expected } \\
\text { Utility }\end{array}$} & \multicolumn{2}{|c|}{ Rank Dependent } & \multirow{2}{*}{$\begin{array}{c}\text { Mixed } \\
\text { Fanning } \\
\end{array}$} & \multirow{2}{*}{$\begin{array}{l}\text { Prospect } \\
\text { Theory }\end{array}$} \\
\hline & & & Convex & Concave & & \\
\hline SSSS & 41 & 0.08 & 0.08 & 0.043 & 0.044 & 0.050 \\
\hline SSSR & 33 & & & 0.004 & 0.003 & 0.005 \\
\hline SSRS & 43 & & & 0.016 & 0.016 & 0.012 \\
\hline SSRR & 132 & & & 0.111 & 0.110 & 0.108 \\
\hline SRSS & 15 & & 0 & & & \\
\hline$S R S R$ & 31 & & $2.3 \mathrm{E}-33$ & & 0.008 & \\
\hline$S R R S$ & 25 & & 0 & & 0.003 & $2.5 \mathrm{E}-33$ \\
\hline$S R R R$ & 91 & & 0 & & 0 & $7.8 \mathrm{E}-34$ \\
\hline$R S S S$ & 20 & & & 0.0122 & & \\
\hline$R S S R$ & 49 & & & 0.012 & 0.016 & \\
\hline$R S R S$ & 43 & & & $4.9 \mathrm{E}-05$ & 0.011 & 0.003 \\
\hline$R S R R$ & 192 & & & 0.085 & 0.094 & 0.096 \\
\hline$R R S S$ & 50 & & 0 & & & \\
\hline$R R S R$ & 110 & & $2.9 \mathrm{E}-33$ & & 0.044 & \\
\hline$R R R S$ & 89 & & $3.5 \mathrm{E}-33$ & & 0.016 & 0 \\
\hline$R R R R$ & 617 & 0.919 & 0.919 & 0.718 & 0.635 & 0.725 \\
\hline Error Rate & & 0.217 & 0.217 & 0.157 & 0.135 & 0.163 \\
\hline mean Log-Likelihood & & -2.248 & -2.248 & -2.186 & -2.184 & -2.188 \\
\hline $\begin{array}{l}\text { Likelihood test } \\
\mathrm{N}\end{array}$ & 1581 & & $0.00(1.00)$ & $194.78(0.000)$ & $201.66(0.000)$ & $188.69(0.000)$ \\
\hline
\end{tabular}

${ }^{a}$ Pattern is based on choices in Lotteries $3,1,2,5$. 
Table 3b. Private Sector Employees

\begin{tabular}{|c|c|c|c|c|c|c|}
\hline \multirow[t]{2}{*}{ Pattern $^{a}$} & \multirow[t]{2}{*}{ Frequency } & \multirow{2}{*}{$\begin{array}{l}\text { Expected } \\
\text { Utility }\end{array}$} & \multicolumn{2}{|c|}{ Rank Dependent } & \multirow{2}{*}{$\begin{array}{c}\text { Mixed } \\
\text { Fanning }\end{array}$} & \multirow{2}{*}{$\begin{array}{c}\text { Prospect } \\
\text { Theory }\end{array}$} \\
\hline & & & Convex & Concave & & \\
\hline$S S S S$ & 17 & 0.0609 & 0.059 & 0.041 & 0.035 & 0.041 \\
\hline$S S S R$ & 10 & & & 0.008 & 0.010 & 0.014 \\
\hline$S S R S$ & 10 & & & 0.011 & 0.011 & 0.010 \\
\hline$S S R R$ & 26 & & & 0.034 & 0.040 & 0.030 \\
\hline$S R S S$ & 5 & & $2.5 \mathrm{E}-33$ & & & \\
\hline$S R S R$ & 11 & & 0 & & 0.009 & \\
\hline$S R R S$ & 10 & & $3.1 \mathrm{E}-34$ & & 0.011 & $1.5 \mathrm{E}-33$ \\
\hline$S R R R$ & 23 & & $6.8 \mathrm{E}-33$ & & $1.6 \mathrm{E}-32$ & $2.28 \mathrm{E}-33$ \\
\hline$R S S S$ & 3 & & & $2.1 \mathrm{E}-33$ & & \\
\hline$R S S R$ & 19 & & & 0.022 & 0.01 & \\
\hline$R S R S$ & 12 & & & 0.001 & 0.008 & 0 \\
\hline$R S R R$ & 62 & & & 0.024 & 0.063 & 0.041 \\
\hline$R R S S$ & 20 & & 0.011 & & & \\
\hline$R R S R$ & 62 & & 0.032 & & 0.086 & \\
\hline$R R R S$ & 43 & & $3.0 \mathrm{E}-33$ & & 0.040 & 0.004 \\
\hline$R R R R$ & 336 & 0.939 & 0.897 & 0.858 & 0.669 & 0.859 \\
\hline Error Rate & & 0.163 & 0.154 & 0.136 & 0.084 & 0.139 \\
\hline mean Log-Likelihood & & -1.941 & -1.938 & -1.922 & -1.907 & -1.925 \\
\hline $\begin{array}{l}\text { Likelihood test } \\
\mathrm{N}\end{array}$ & 669 & & $3.74(0.81)$ & $25.38(0.001)$ & $45.71(0.000)$ & $21.54(0.006)$ \\
\hline
\end{tabular}

${ }^{a}$ Pattern is based on choices in Lotteries 3, 1, 2, 5 . 
Table 3c. Entrepreneurs - Garment Industry

\begin{tabular}{|c|c|c|c|c|c|c|}
\hline \multirow[t]{2}{*}{ Pattern $^{a}$} & \multirow[t]{2}{*}{ Frequency } & \multirow{2}{*}{$\begin{array}{l}\text { Expected } \\
\text { Utility }\end{array}$} & \multicolumn{2}{|c|}{ Rank Dependent } & \multirow{2}{*}{$\begin{array}{c}\text { Mixed } \\
\text { Fanning }\end{array}$} & \multirow{2}{*}{$\begin{array}{l}\text { Prospect } \\
\text { Theory }\end{array}$} \\
\hline & & & Convex & Concave & & \\
\hline$S S S S$ & 11 & 0.109 & 0.103 & 0.062 & 0.069 & 0.080 \\
\hline$S S S R$ & 4 & & & 0 & 0 & 0 \\
\hline$S S R S$ & 10 & & & 0.017 & 0.020 & 0.010 \\
\hline$S S R R$ & 27 & & & 0.117 & 0.117 & 0.114 \\
\hline$S R S S$ & 5 & & 8.9E-33 & & & \\
\hline$S R S R$ & 4 & & $1.7 \mathrm{E}-32$ & & $1.1 \mathrm{E}-32$ & \\
\hline$S R R S$ & 4 & & 0 & & $5.5 \mathrm{E}-33$ & 0 \\
\hline$S R R R$ & 17 & & $4.0 \mathrm{E}-34$ & & $1.5 \mathrm{E}-32$ & 0 \\
\hline$R S S S$ & 5 & & & 0.033 & & \\
\hline$R S S R$ & 11 & & & 0.015 & 0.017 & \\
\hline$R S R S$ & 7 & & & $6.3 \mathrm{E}-33$ & 0 & $1.6 \mathrm{E}-33$ \\
\hline$R S R R$ & 32 & & & 0.045 & 0.075 & 0.071 \\
\hline$R R S S$ & 18 & & 0.040 & & & \\
\hline$R R S R$ & 22 & & 0 & & 0.078 & \\
\hline$R R R S$ & 18 & & 0 & & 0.046 & 0.031 \\
\hline$R R R R$ & 105 & 0.891 & 0.857 & 0.712 & 0.578 & 0.695 \\
\hline Error Rate & & 0.234 & 0.223 & 0.176 & 0.149 & 0.181 \\
\hline mean Log-Likelihood & & -2.356 & -2.353 & -2.311 & -2.305 & -2.314 \\
\hline $\begin{array}{l}\text { Likelihood test } \\
\text { N }\end{array}$ & 300 & & $1.92(0.96)$ & $27.20(0.000)$ & $30.79(0.001)$ & $24.90(0.002)$ \\
\hline
\end{tabular}

${ }^{a}$ Pattern is based on choices in Lotteries $3,1,2,5$. 
Table 3d. Vegetable Whole Traders

\begin{tabular}{|c|c|c|c|c|c|c|}
\hline \multirow[t]{2}{*}{ Pattern $^{a}$} & \multirow[t]{2}{*}{ Frequency } & \multirow{2}{*}{$\begin{array}{c}\text { Expected } \\
\text { Utility }\end{array}$} & \multicolumn{2}{|c|}{ Rank Dependent } & \multirow{2}{*}{$\begin{array}{c}\text { Mixed } \\
\text { Fanning } \\
\end{array}$} & \multirow{2}{*}{$\begin{array}{l}\text { Prospect } \\
\text { Theory }\end{array}$} \\
\hline & & & Convex & Concave & & \\
\hline SSSS & 5 & 0.089 & 0.086 & 0.036 & 0.041 & 0.050 \\
\hline SSSR & 6 & & & 0.013 & 0.008 & 0.014 \\
\hline SSRS & 7 & & & 0.025 & 0.016 & 0.010 \\
\hline SSRR & 33 & & & 0.181 & 0.179 & 0.181 \\
\hline SRSS & 3 & & $3.0 \mathrm{E}-33$ & & & \\
\hline$S R S R$ & 3 & & $7.8 \mathrm{E}-34$ & & 0.013 & \\
\hline$S R R S$ & 4 & & 0 & & 0.020 & 0.017 \\
\hline$S R R R$ & 9 & & 0.036 & & 0 & $5.7 \mathrm{E}-33$ \\
\hline$R S S S$ & 5 & & & 0.027 & & \\
\hline$R S S R$ & 9 & & & 0.019 & 0.038 & \\
\hline$R S R S$ & 6 & & & $4.9 \mathrm{E}-33$ & 0.015 & 0.007 \\
\hline$R S R R$ & 44 & & & 0.220 & 0.210 & 0.248 \\
\hline$R R S S$ & 3 & & 0 & & & \\
\hline$R R S R$ & 5 & & $1.9 \mathrm{E}-32$ & & $4.4 \mathrm{E}-34$ & \\
\hline$R R R S$ & 5 & & 0 & & $1.15 \mathrm{E}-34$ & 0 \\
\hline$R R R R$ & 81 & 0.91 & 0.878 & 0.478 & 0.460 & 0.474 \\
\hline Error Rate & & 0.248 & 0.244 & 0.103 & 0.090 & 0.113 \\
\hline mean Log-Likelihood & & -2.373 & -2.372 & -2.124 & -2.123 & -2.133 \\
\hline $\begin{array}{l}\text { Likelihood test } \\
\mathrm{N}\end{array}$ & 228 & & $0.31(1.00)$ & $113.80(0.000)$ & $113.95(0.001)$ & $109.50(0.002)$ \\
\hline
\end{tabular}

${ }^{a}$ Pattern is based on choices in Lotteries $3,1,2,5$. 
Table 3e. Peasants

\begin{tabular}{|c|c|c|c|c|c|c|}
\hline \multirow[t]{2}{*}{ Pattern $^{a}$} & \multirow[t]{2}{*}{ Frequency } & \multirow{2}{*}{$\begin{array}{l}\text { Expected } \\
\text { Utility }\end{array}$} & \multicolumn{2}{|c|}{ Rank Dependent } & \multirow{2}{*}{$\begin{array}{c}\text { Mixed } \\
\text { Fanning }\end{array}$} & \multirow{2}{*}{$\begin{array}{l}\text { Prospect } \\
\text { Theory }\end{array}$} \\
\hline & & & Convex & Concave & & \\
\hline$S S S S$ & 8 & 0.065 & 0.0578 & 0.023 & 0.026 & 0.027 \\
\hline$S S S R$ & 13 & & & 0 & 0.0134 & 0.008 \\
\hline$S S R S$ & 16 & & & $3.3 \mathrm{E}-04$ & 0.020 & 0.006 \\
\hline$S S R R$ & 46 & & & 0.256 & 0.174 & 0.203 \\
\hline$S R S S$ & 2 & & 0 & & & \\
\hline$S R S R$ & 13 & & 0 & & 0.016 & \\
\hline$S R R S$ & 7 & & $4.8 \mathrm{E}-32$ & & 0 & 0 \\
\hline$S R R R$ & 42 & & 0.181 & & 0.083 & 0.068 \\
\hline$R S S S$ & 7 & & & 0.010 & & \\
\hline$R S S R$ & 10 & & & $6.9 \mathrm{E}-33$ & 0 & \\
\hline$R S R S$ & 18 & & & 0.030 & 0.044 & 0.045 \\
\hline$R S R R$ & 54 & & & 0.102 & 0.145 & 0.126 \\
\hline$R R S S$ & 9 & & $7.8 \mathrm{E}-33$ & & & \\
\hline$R R S R$ & 21 & & $5.3 \mathrm{E}-33$ & & 0.027 & \\
\hline$R R R S$ & 23 & & $1.5 \mathrm{E}-32$ & & 0.025 & $2.2 \mathrm{E}-34$ \\
\hline$R R R R$ & 95 & 0.935 & 0.762 & 0.581 & 0.426 & 0.517 \\
\hline Error Rate & & 0.294 & 0.275 & 0.207 & 0.157 & 0.191 \\
\hline mean Log-Likelihood & & -2.501 & -2.489 & -2.397 & -2.394 & -2.395 \\
\hline $\begin{array}{l}\text { Likelihood test } \\
\mathrm{N}\end{array}$ & 384 & & $9.03(0.25)$ & $79.73(0.000)$ & $82.44(0.001)$ & $81.63(0.002)$ \\
\hline
\end{tabular}

${ }^{a}$ Pattern is based on choices in Lotteries $3,1,2,5$. 


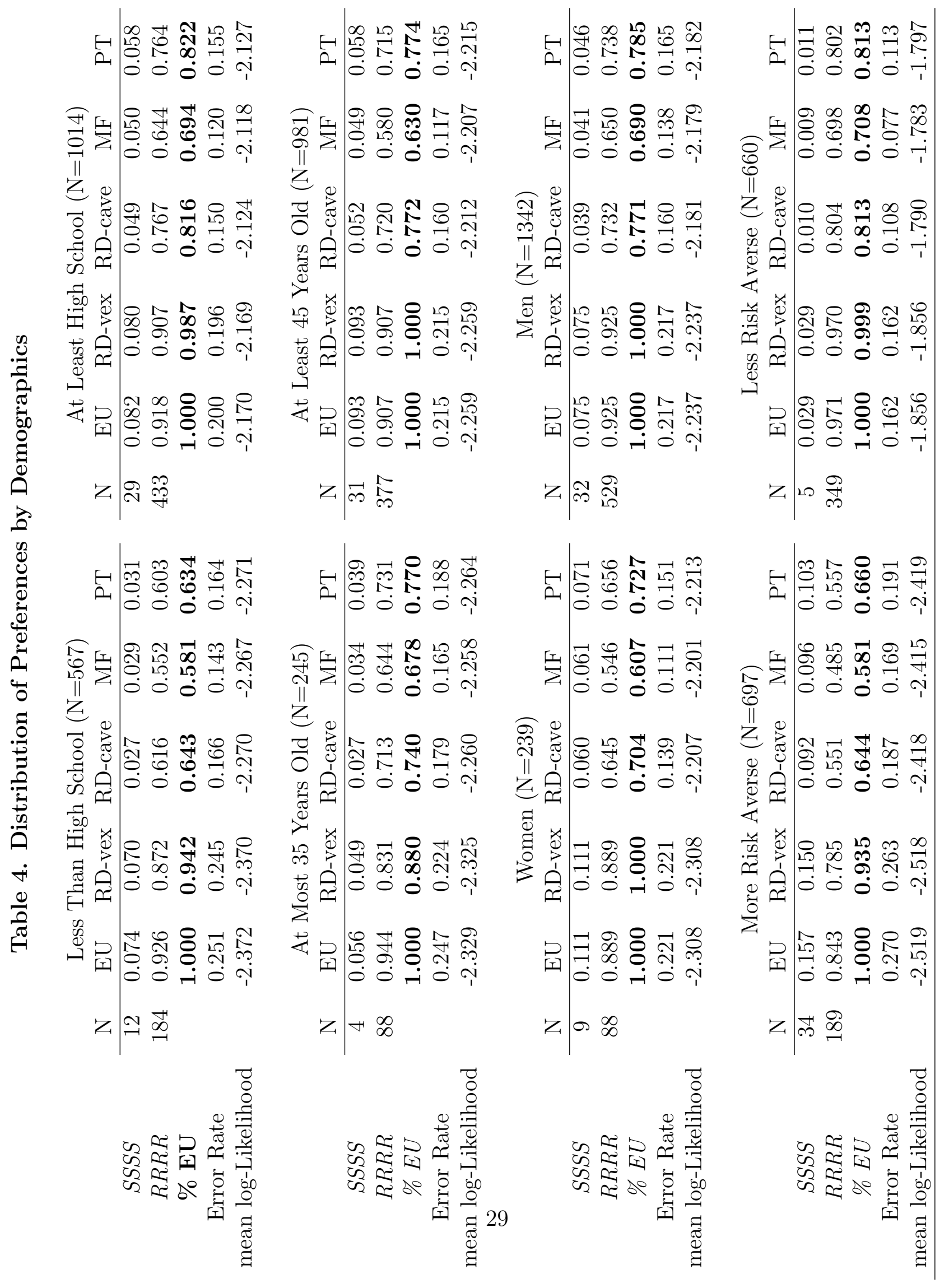




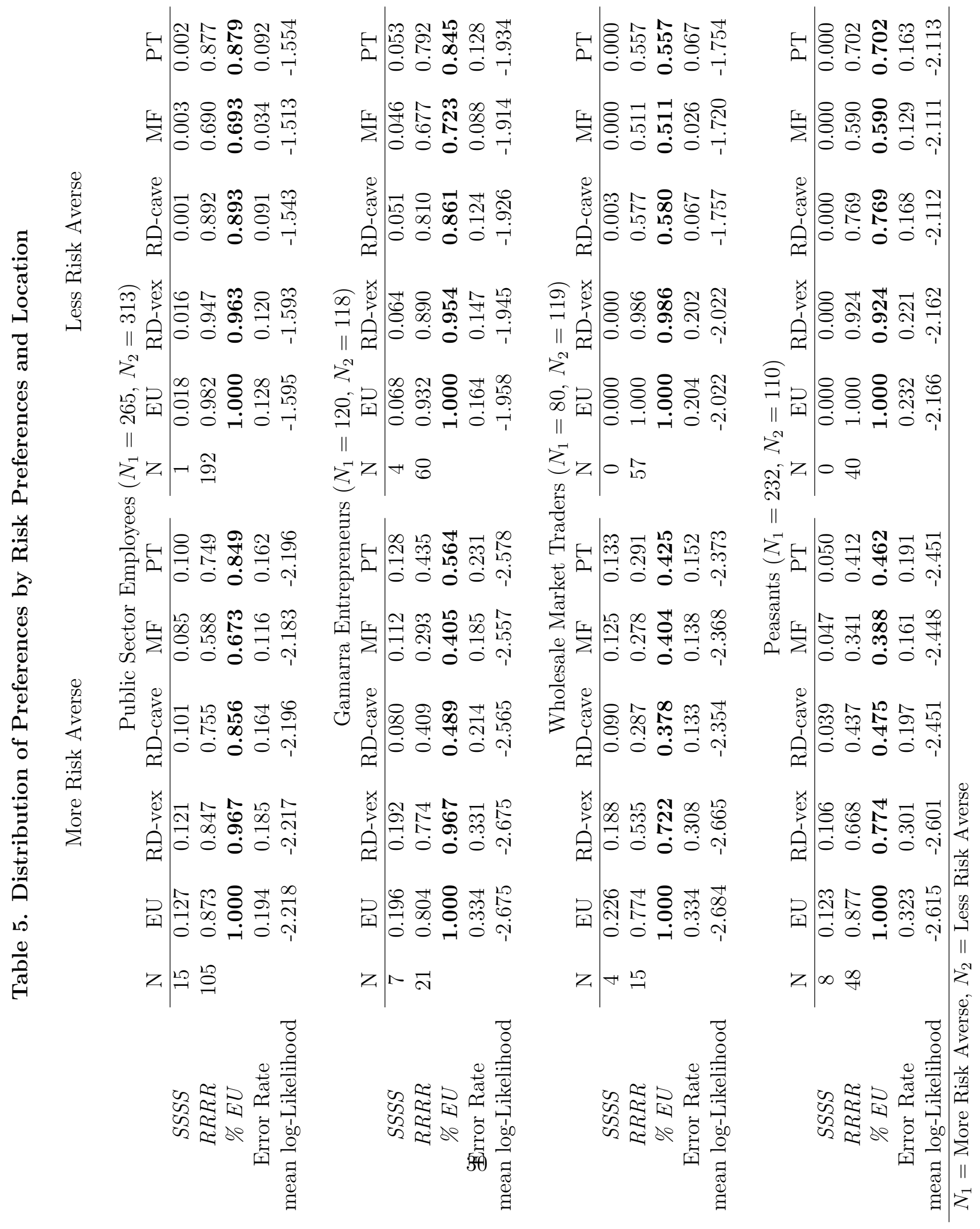




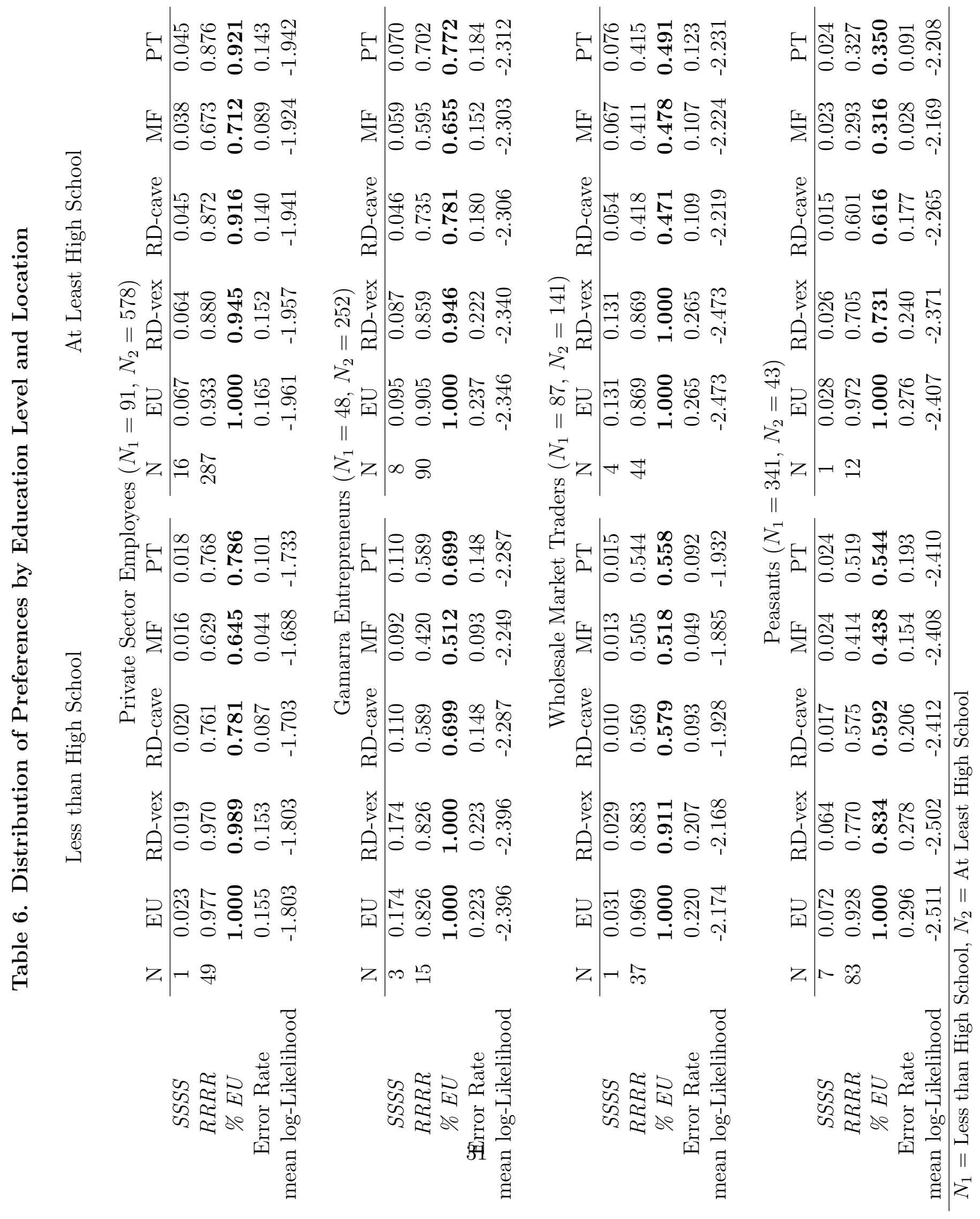


Table 7. Parametric Estimates

\begin{tabular}{|c|c|c|c|c|}
\hline & \multicolumn{4}{|c|}{ Behavioral Model } \\
\hline & RD-vex & RD-cave & $\mathrm{MF}$ & $\mathrm{PT}$ \\
\hline$S S S S$ & $0.278(1.345)$ & $0.011(0.045)$ & $0.037(0.029)$ & $0.046(0.047)$ \\
\hline$S S S R$ & & $0.019(0.035)$ & & $0.017(0.037)$ \\
\hline$S S R S$ & & $0.056(0.037)$ & $0.039(0.032)$ & $0.040(0.038)$ \\
\hline$S S R R$ & & $0.463^{* * *}(0.085)$ & $0.340 *(0.181)$ & $0.470^{* * *}(0.082)$ \\
\hline$S R S S$ & $0(0)$ & & & \\
\hline$S R S R$ & $0(0)$ & & $0.031(0.025)$ & \\
\hline$S R R S$ & $0(0)$ & & $0.003(0.019)$ & $0(0)$ \\
\hline$S R R R$ & $0.472(1.771)$ & & $0.007(0.042)$ & $0(0)$ \\
\hline$R S S S$ & & $0.060^{* *}(0.029)$ & $0(0)$ & $0(0)$ \\
\hline$R S S R$ & & $0.018(0.041)$ & $0.041(0.034)$ & \\
\hline$R S R S$ & & $0.006(0.038)$ & $0.034(0.032)$ & $0.037(0.040)$ \\
\hline$R S R R$ & & $0.365^{* * *}(0.068)$ & $0.269^{*}(0.143)$ & $0.389^{* * *}(0.075)$ \\
\hline$R R S S$ & $0(0)$ & & & \\
\hline$R R S R$ & $0(0)$ & & $0.049(0.051)$ & \\
\hline$R R R S$ & $0(0)$ & & $0.028(0.040)$ & 7.3E-06 (0.051) \\
\hline \multirow[t]{2}{*}{$R R R R$} & $0.250(3.075)$ & 4.6E-06 (0.094) & $0.121(0.426)$ & $7.1 \mathrm{E}-06(0.092)$ \\
\hline & \multicolumn{4}{|c|}{ Expected Utility } \\
\hline$S S S S$ & $0.057(0.099)$ & $0.052^{* * *}(0.015)$ & $0.050^{* * *}(0.015)$ & $0.052^{* * *}(0.015)$ \\
\hline$R R R R$ & $0.943^{* * *}(0.099)$ & $0.948^{* * *}(0.015)$ & $0.950^{* * *}(0.015)$ & $0.948^{* * *}(0.015)$ \\
\hline \multirow[t]{2}{*}{ Error Rate } & $0.210^{* * *}(0.017)$ & $0.157^{* * *}(0.007)$ & $0.145^{* * *}(0.011)$ & $0.161^{* * *}(0.007)$ \\
\hline & \multicolumn{4}{|c|}{ Share Equation } \\
\hline Constant & $-0.023(0.530)$ & $-0.428(3.823)$ & $-0.372(3.194)$ & $-0.444(2.471)$ \\
\hline Male & $0.102(1.675)$ & $0.229(0.329)$ & $0.285^{*}(0.158)$ & $0.240(0.277)$ \\
\hline Age & $-0.038(1.627)$ & $0.337(1.919)$ & $-0.012(0.065)$ & $0.312(2.427)$ \\
\hline At Least Primary & $0.322(9.625)$ & $-0.095(1.456)$ & $-0.323(2.883)$ & $-0.065(0.316)$ \\
\hline At Least Secondary & $0.495(3.031)$ & $0.042(0.064)$ & $0.055(0.066)$ & $0.045(0.064)$ \\
\hline Garment District & $-0.390(5.569)$ & $0.805^{* * *}(0.316)$ & $0.705(0.531)$ & $0.847^{* * *}(0.334)$ \\
\hline Peasant Community & $-0.447(3.095)$ & $0.176(0.303)$ & $9.4 \mathrm{E}-04(0.265)$ & $0.187(0.325)$ \\
\hline Private Sector & $0.863(8.597)$ & $2.237^{* * *}(0.376)$ & $2.123^{* * *}(0.748)$ & $2.268^{* * *}(0.409)$ \\
\hline mean-Likelihood & -2.239 & -2.154 & -2.153 & -2.156 \\
\hline Observations & 1581 & 1581 & 1581 & 1581 \\
\hline
\end{tabular}

Standard errors in parentheses. ${ }^{*}$ p-value $<0.10,{ }^{* *}$ p-value $<0.05,{ }^{* * *}$ p-value $<0.01$ 